\title{
Concepções de adultos recém-escolarizados sobre escrita e letramento
}

\author{
Patrícia Cardoso Batista \\ Universidade Estadual de Londrina \\ patty_jbt@hotmail.com \\ Ana Lúcia de Campos Almeida \\ Universidade Estadual de Londrina \\ analucpos@gmail.com \\ Rosangela Maria de Almeida Netzel \\ Universidade Estadual de Londrina \\ rosalm@alunos.utfpr.edu.br
}

\section{Resumo}

Nesta pesquisa, realizada com recém-escolarizados da Educação de Jovens e Adultos (EJA), buscou-se investigar o valor atribuído à cultura escrita. Desse modo, a questão principal de investigação é: que concepções os egressos da Educação de Jovens e Adultos têm sobre a escrita? Essa é uma questão relevante, pois é importante compreender o ponto de vista desses adultos sobre o cotidiano na sociedade letrada e a avaliação que fazem quanto ao impacto da EJA em suas práticas sociais. Para tanto, empregou-se como encaminhamento metodológico a pesquisa de campo, de cunho qualitativo, a partir de entrevistas semiestruturadas com quatro pessoas que frequentaram essa modalidade escolar. Adicionalmente, foi desenvolvida uma análise textual discursiva, elencando os dados em categorias. Como fundamentos teóricos, adotou-se os Estudos do Letramento, estudos de Linguística e Linguística Aplicada, bem como noções dos campos da sociologia, antropologia e estudos culturais. Por fim, foram destacados os benefícios que os participantes atribuem às suas práticas sociais a partir do aprendizado ou do aprimoramento da linguagem escrita. Por meio desta discussão, pretendeu-se contribuir para que os estudantes da EJA sejam compreendidos por pesquisadores e educadores, motivando intervenções que favoreçam esse público.

Palavras-chave: letramento; oralidade; escrita; adultos. 


\begin{abstract}
In this research, carried out with newly enrolled students of the "Youth and Adult Education" (EJA), we seek to investigate the value attributed to the written culture. Thus, the main question of research is: what conceptions do graduates of "Youth and Adult Education" have about writing? This is a relevant issue because it's important to understand the adults' point of view about the daily life in the literate society and their evaluation regarding the impact of EJA on their social practices. We have used as methodological procedures filiated to the qualitative research field, semi-structured interviews with four people who attended this school modality, and we have developed discursive textual analysis, organizing the data in categories. As a theoretical basis, we have adopted mainly the New Literacy Studies, some conceptions from Linguistics and Applied Linguistic Studies and notions from Sociology, Anthropology and Cultural Studies as well. Finally, we have highlighted the benefits that participants attribute to literacy acquisition in their social practices from that moment on. With this discussion, we intend to produce knowledge about to the students of EJA program, which may help researchers and educators to improve understanding this public, motivating a growth of interventions in their $\mathrm{t}$ favor.
\end{abstract}

Keywords: literacy; orality; writing; adults.

\title{
1 Introdução
}

O Brasil é um país com grande desenvolvimento urbano, marcado pela cultura grafocêntrica, de modo que as práticas sociais centralizadas na escrita adquirem relevância para seus cidadãos. Assim, a escrita é utilizada constantemente, presente nos letreiros dos ônibus; nas placas das ruas; nas vitrines das lojas; nos folhetos das igrejas; nos conteúdos veiculados pelas mídias impressas e digitais; nas mensagens recebidas no celular; etc.

Para indivíduos letrados, esses usos são corriqueiros, mas "representam verdadeiros obstáculos para os grandes grupos de brasileiros não-escolarizados, que não tiveram acesso à escola, ou foram prematuramente expulsos dela." (KLEIMAN, 2008, p. 7). Um simples ato, como identificar o número da poltrona ao fazer uso de um ônibus, pode vir a ser uma atividade difícil, que demanda esforços e, por vezes, auxílio de alguém que realize essa prática letrada. 
Trata-se de um grande número de jovens e adultos que, não possuindo habilidades relacionadas ao código escrito, buscam estratégias de participação social. Entendemos que o analfabetismo não os faz inferiores aos demais, de modo que seus direitos precisam ser respeitados na mesma medida que os dos demais cidadãos, pois o conhecimento escolar não é o único valor relacionado à cidadania.

No entanto, a aquisição e o aprimoramento dos usos da escrita e da leitura, normalmente, se dão no ambiente escolar. Desse modo, quem não tem ou não teve acesso à escolarização regular sofre grande prejuízo, pois, segundo Kleiman (2008, p. 8), habilidades escolares são "formas de se potencializar o cidadão para lidar com as estruturas de poder na sociedade.”.

Assim, concordando com Kleiman, entendemos que as pessoas que não sabem ler e escrever estão em desvantagem perante a sociedade atual, já que "a aquisição da leitura é imprescindível para agir com autonomia nas sociedades letradas." (SOLÉ, 1998, p. 32).

Essa autonomia permite ao indivíduo ser bem-sucedido em situações da vida social cotidiana. Deste modo, a escrita, mais que uma tecnologia, tornou-se um bem social indispensável na sociedade contemporânea, "não por virtudes que lhe são imanentes, mas pela forma como se impôs e a violência com que penetrou nas sociedades modernas e impregnou as culturas de um modo geral [...], chegando a simbolizar educação, desenvolvimento e poder. " (MARCUSCHI, 2001, p. 16-17).

Tamanha valorização leva também à discriminação daqueles que não dominam o código escrito. Corroborando essa ideia, Signorini (2008) aponta que, no Brasil, a hierarquização socioeconômica refletese nas desigualdades de acesso à escrita e à cultura letrada.

Diante dessas considerações, o texto que se apresenta tem como objetivo contribuir com a discussão sobre a importância da aquisição da escrita para adultos e com a exposição sobre alguns mitos em torno do letramento. A questão principal de nossa investigação é: que concepções os egressos da Educação de Jovens e Adultos têm sobre a escrita?

Quanto à metodologia, trata-se de uma pesquisa de campo, de cunho qualitativo, de modo que os dados analisados resultam de entrevistas semiestruturadas com quatro pessoas que retomaram seus estudos na fase adulta na modalidade de Educação de Jovens e Adultos (EJA), no município de Londrina (PR). Como fundamentos teóricos 
adotamos principalmente conceitos dos Novos Estudos do Letramento, bem como noções oriundas dos estudos linguísticos, sociológicos e antropológicos, relacionando-os às concepções que os participantes apresentam em suas falas.

As reflexões aqui empreendidas são relevantes, à medida que permitem entender o valor atribuído à aquisição da escrita por adultos recém-escolarizados, inseridos numa sociedade de cultura predominantemente grafocêntrica. Desse modo pretendemos, ainda, contribuir para que os estudantes dessa modalidade sejam melhor compreendidos pelos acadêmicos e educadores, motivando-os à promoção de intervenções que favoreçam esse público.

\section{A educação de jovens e adultos no Brasil}

As iniciativas para atendimento de pessoas que não tiveram acesso à educação na infância no Brasil têm se efetivado sob o título de Educação de Jovens e Adultos (EJA), modalidade da Educação Básica, conforme a Lei de Diretrizes da Educação Nacional (LDBEN) 9.394/96, nos Art. 37 e 38 (BRASIL, 1996). A chamada pública, essencial para a montagem de turmas, visto que a matrícula não é obrigatória como ocorre com outras modalidades da educação básica, é importante também no acesso desse público ao segmento de acordo com o parágrafo primeiro do Art. $5^{\circ}$ da mesma lei.

Segundo o histórico presente nas Diretrizes Curriculares da Educação de Jovens e Adultos (PARANÁ, 2006), as práticas de EJA, no decorrer da história brasileira, estiveram atreladas a condições políticas e sociais, desde sua formalização - como iniciativa educacional - ao final do século XIX. Por volta de 1960, a figura de Paulo Freire foi um grande marco para a modalidade, focalizando a importância dos saberes dos educandos, relacionados à cultura de suas comunidades, à própria capacidade de reflexão e de conscientização a partir da leitura da Palavra-mundo. Paulo Freire antecipou concepções dos Novos Estudos de Letramento e da perspectiva de um letramento crítico, em que os educandos não recebem a escrita como um código a ser manuseado minimamente, mas como a instauração de um processo dialético de reflexão crítica por meio da aquisição e sistematização da linguagem escrita. A reflexão crítica é a base da educação emancipatória 
postulada por Freire $(1987 ;$ 1996). Ainda segundo o educador, a aproximação entre o universo de vivência do sujeito e as práticas da escrita precisam ocorrer de forma gradativa e contextualizada, de modo que as práticas letradas venham a se somar à leitura de mundo do sujeito (FREIRE, 2001).

Porém, nas décadas seguintes, sob o governo da ditadura militar, houve a oferta de ensino de leitura/escrita pautado em uma abordagem meramente instrumental, como ocorreu no Movimento Brasileiro de Alfabetização (Mobral), fato que ampliou a existência do analfabetismo funcional. ${ }^{1}$ Com a redemocratização, a partir de 1984 , outras iniciativas de EJA voltaram a se fortalecer. No entanto, o Brasil chegou ao século XXI com um número exorbitante ${ }^{2}$ de analfabetos, necessitando de muitas políticas públicas comprometidas para a superação dessa realidade.

Nesse contexto, a escola é posta como disseminadora do conhecimento, em um processo conjunto entre educandos e educadores, diante dos desafios da realidade e em busca de uma sociedade igualitária, tornando "possível ampliar a leitura de mundo, pela mediação entre os conhecimentos e os indivíduos, favorecendo assim o acesso à cultura e a elaboração de saberes pelos próprios sujeitos da prática educativa." (MOREIRA, 1994 apud PARANÁ, 2006, p. 37). Nas referidas diretrizes, aponta-se, ainda, que a EJA pode funcionar como parte integrante das redes de ensino, por meio de programas de alfabetização ou de iniciativas governamentais contínuas no âmbito dos sistemas educacionais, envolvendo carga horária diferenciada e exames que insiram os estudantes em diferentes níveis educacionais.

A taxa de analfabetismo, explicitada anteriormente em nota de rodapé, equivalente a 7,2\% da população acima de 15 anos de idade, encontra-se longe da meta apontada no Plano Nacional de Educação

\footnotetext{
${ }^{1}$ Analfabetismo funcional é denominado o processo em que o educando adquire o código convencional da escrita de uma língua, ou seja, é capaz de decodificar a correspondência fonema/grafema, sem, no entanto, conseguir utilizá-lo funcionalmente, isto é, comunicativamente, na compreensão de mensagens escritas.

${ }^{2}$ A atual taxa de analfabetismo no país, segundo Ferreira (2017), com base em dados do Instituto Brasileiro de Geografia e Estatística (IBGE), corresponde a 11,8 milhões de pessoas, 7,2 por cento da população acima de 15 anos de idade.
} 
(PNE) (BRASIL, 2014). Neste sentido, entendemos que a EJA se constitui como espaço que favorece o acesso à escolarização desse público. Observamos, contudo, que o fato de descrevermos os participantes desta pesquisa como egressos da EJA, não significa que eles tenham necessariamente completado as etapas de escolarização, mas sim que participaram da modalidade por certo período de tempo.

\section{Escrita e letramento na sociedade contemporânea}

A transição da língua exclusivamente oral para uma ou mais variedades linguísticas escritas, com sua aprendizagem implementada por meio de uma escola formal, envolve um processo complexo abrangente da totalidade das relações sociais e culturais, pois a língua eleita como padrão foi definida a partir da variedade falada pelas classes dominantes, ligadas ao poder. No entanto, segundo Gnerre (2001), há uma falsa aparência de neutralidade no código escrito legitimado pelo Estado, ocultando-se que ele atende a interesses restritos e, por vezes, até discriminatórios. Nesse contexto, os dicionários e gramáticas são instrumentos centrais no processo de controle da língua, pois a norma denominada "culta" é fixada oficialmente a partir de seus registros. O fato de se legitimar como padrão a variedade falada pelas classes dominantes e a instauração de poderosos instrumentos oficiais de registro e controle, determina, em grande medida, o estabelecimento de uma desigualdade na distribuição e utilização da língua como bem cultural. Por isso, de acordo com Gnerre (2001, p. 22), "a linguagem constitui o arame farpado mais poderoso para bloquear o acesso ao poder.".

A escrita, nessa perspectiva, por vezes, ao invés de ser utilizada para difusão de ideias, pode servir para "ocultar, para garantir o poder àqueles que a ela têm acesso. " (TFOUNI, 2000, p. 11). Um exemplo seria o fato de o catolicismo ter se utilizado por muitos anos de textos em latim, com a leitura da Bíblia oralizada somente pelo clero, o que mudou somente diante da popularização de outras religiões que usavam a língua vernácula, sendo mantida sempre a norma-padrão, que exige grande domínio do código escrito.

Como nesse exemplo da esfera religiosa, muitos outros setores excluem a grande população, sobretudo os analfabetos, da participação 
em suas práticas, por meio do uso exacerbado do código escrito e da utilização exclusiva da variedade de prestígio, propositalmente. Fato justificado, por vezes, apontando-se a escrita como espaço de formalidade e de organização, enquanto a fala é tida como lugar de caos e de improvisação.

Apesar de essa dicotomia vir sendo desmistificada por diversos autores, aqueles que não dominam a escrita incorporam esse modo de conceber a escrita como significativamente superior à fala. A supervalorização da escrita, enquanto código que não dominam, os faz desenvolverem um sentimento de menos valia e de desprestígio social, inclusive por se verem excluídos de participar de diversas práticas sociais de letramento em que o escrito prevalece.

Nessa perspectiva, Rama (2015) apresenta a fundação da cidade moderna como espaço de práticas burocráticas, com o estabelecimento dos registros escritos para validar as posses, para localização dos endereços, das certidões e serviços múltiplos que envolvem a escrita. $\mathrm{Na}$ cidade letrada, como denominada pelo autor, a burocracia estabelecida exige registro escrito para as práticas terem validade. Assim, somente um grupo letrado que domine a norma-padrão terá o poder de reivindicar e ser atendido por sua condição de redigir atas e ofícios. Essa habilidade pressupõe domínio não só da língua, mas também de gêneros textuais, o que é superior à condição de um indivíduo minimamente alfabetizado, sem domínio das práticas do letramento dominante.

Desse modo, constata-se que a escrita permanece com maior status em nossa sociedade, que a supervaloriza em relação à fala. Isso implica o estabelecimento da dicotomia a que nos referimos anteriormente, tomando-se a escrita como estável, complexa e organizada ao seguir a norma-padrão. Já a fala aparece como estruturalmente simples, instável e repleta de erros gramaticais.

Marcuschi (2001) combate essa ideia, postulando que fala e escrita são modalidades complementares, imbuídas de traços cognitivos e sociais, pautadas em práticas e usos reais, de modo que a escrita não é uma mera representação da fala. Há, assim, segundo o autor, um contínuo de gêneros textuais/discursivos, que podem ser mais aproximados das marcas da oralidade ou da escrita. "A língua, seja na sua modalidade falada ou escrita, reflete, em boa medida, a organização da sociedade. Isso porque a própria língua mantém complexas relações 
com as representações e formações sociais." (MARCUSCHI, 2001, p. 35, grifo do autor).

Por conseguinte, enfatizamos que oralidade e escrita exercem papel crucial, mas deve haver cuidado para não confundir suas funções e contextos de uso, pois tanto a fala quanto a escrita não operam e nem se constituem em uma única dimensão expressiva.

Há apontamentos, como os de Gnerre (2001), de que os estudos em torno da escrita têm crescido nas diversas áreas, devido, provavelmente, à oferta de espaços de alfabetização e educação em todo o mundo e ao movimento de padronização da escrita em muitas línguas. Porém, por trás dessas iniciativas, pode subsistir uma visão enraizada na dicotomia entre fala e escrita, que coloca os analfabetos em um nível inferior por não dominarem o código escrito.

Nesse sentido, ao investigar as campanhas de incentivo à alfabetização na década de 1990, Street (2014) aponta o tratamento estigmatizante e discriminatório com que a mídia se refere aos analfabetos, relacionando-os à ignorância, ao atraso mental e à incapacidade social, com utilização de metáforas sobre cegueira e escuridão em relação à ausência de cultura letrada. Street também considera que há um processo de construção e de propagação de falsas expectativas sobre melhorias advindas diretamente da escolarização em relação ao trabalho, mobilidade social e realização pessoal, uma vez que esses elementos se encontram influenciados por fatores como classe social, gênero e etnia, e não somente por níveis de alfabetização ou letramento (GRAFF, 1979 apud STREET, 2014).

Há ainda outros estudos sobre o analfabetismo a serem considerados, como os de Matencio (2008) e de Ratto (2008), que reiteram que a relação de dominação e poder entre letrados e iletrados define formas discursivas na sociedade contemporânea, pressupondo que somente o saber e o conhecimento derivado da ciência têm valor, como se outros saberes não tivessem validade. Essa relação de poder afeta a vida dos não alfabetizados e pode levá-los a um sentimento de inferioridade e de baixa autoestima.

Devemos, portanto, atentar para o valor atribuído à escrita em detrimento da oralidade e atuar contra a discriminação dos não alfabetizados ou não escolarizados. Assim, apesar da utilização da escrita ser uma estratégia eficaz nas práticas sociais e na compreensão de discursos que nos rodeiam, a realidade é permeada por outros fatores, 
observando-se que a alfabetização, implementada em determinadas campanhas mundiais, parece ter servido às demandas da industrialização para preparar mão de obra capaz de seguir instruções. Em uma visão de educação libertadora freiriana, entende-se a necessidade da escrita ser utilizada para o desenvolvimento de reflexão crítica, mas isso não quer dizer que os alfabetizados sejam críticos e os analfabetos sejam alienados.

$\mathrm{Na}$ contramão da dicotomia entre fala e escrita e da supervalorização dos usos escritos, o termo letramento começou a ser usado no Brasil em 1980, derivado do vocábulo literacy, de origem inglesa, numa tentativa de separar os estudos sobre o impacto social da escrita dos estudos sobre alfabetização. A alfabetização refere-se à aquisição do código escrito, já o letramento refere-se a um "conjunto de práticas sociais que usam a escrita como sistema simbólico e como tecnologia, em contextos específicos, para objetivos específicos." (KLEIMAN, 2008, p. 19). Assim, as práticas sociais de letramento são sempre situadas em ambientes específicos, de acordo com objetivos específicos de uso, e variam em função das diferentes comunidades em que os textos escritos se inserem, adquirindo valor e significado distintos. (BARTON; HAMILTON; IVANIC, 1994; 2000).

Segundo a definição de Soares (2010), há diferença entre a pessoa que não sabe ler e escrever - analfabeta -, aquela que somente sabe ler e escrever - alfabetizada - e outra que faz uso da leitura e da escrita - de modo a ser letrada. Assim, o letramento é tido como "estado ou condição de quem sabe ler e escrever e pratica a leitura e a escrita." (SOARES, 2010, p. 36).

Como se pode observar a partir dessas colocações teóricas, as fronteiras entre letrados e não letrados não são tão óbvias como fazem parecer os "cálculos" individuais de letramento, pois nem todos os tipos de letramento são valorizados socialmente. Nesse sentido, Street (2014) divide o letramento em modelo autônomo, aquele em que a interpretação é tida como independente do contexto, e o modelo ideológico, relacionado ao valor das práticas de letramento em culturas específicas, levando em consideração também a oralidade perpassada pela escrita. Portanto, segundo o mesmo autor, as práticas de letramento não são tecnologias neutras, pois estão associadas a relações de poder e a questões de ideologia. 
Autores como Soares (2010), Rojo (2009), Street (2014) e Kleiman (2008) comentam a dimensão social do letramento, referindose ao uso de habilidades de leitura e escrita em contextos específicos, de acordo com as necessidades, valores culturais, eventos, práticas e contextos sociais. Dessa forma, um dos objetivos da escola seria "promover a interação ativa com a escrita, com a leitura e com o conhecimento científico presentes nas diversas disciplinas. (OLIVEIRA, 2008, p. 155), de modo a possibilitar que os estudantes "participem das várias práticas sociais que se utilizam da leitura e da escrita (letramentos) na vida da cidade, de maneira ética, crítica e democrática." (ROJO, 2009, p. 11).

Diante dessas considerações, percebemos que o indivíduo alfabetizado não é necessariamente um indivíduo letrado. Alfabetizado é aquele que sabe ler e escrever, já letrado é aquele que sabe usar a leitura e a escrita de acordo com demandas sociais. Por outro lado, a partir dos pressupostos dos Novos Estudos de Letramento, pode-se argumentar que o indivíduo não alfabetizado que vive em um centro urbano não deve ser considerado totalmente iletrado, na medida em que consegue se localizar através da leitura de roteiros ou mapas, reconhece o letreiro do ônibus de seu destino e, muitas vezes, participa de determinadas práticas letradas, acompanhando, por exemplo, a leitura da Bíblia ou de outros materiais de circulação social, de modo a desenvolver uma oralidade letrada.

Nesse sentido, "iletramento não existe, enquanto ausência total, nas sociedades industrializadas modernas" (TFOUNI, 2000, p. 24), pois, nelas não há alguém com "grau zero" de letramento.

As pessoas analfabetas utilizam outras estratégias para atuar na sociedade letrada. Isso é possível, porque elas possuem habilidades como memória, percepção e pensamento -, da mesma maneira que as alfabetizadas, sendo capazes de relacionar elementos, associando tempos, espaços e formatos a outros elementos presentes nos símbolos, objetos e práticas cotidianas, de modo a atuar sobre a realidade com eficiência.

Dessa forma, defendemos que é difícil se chegar a uma definição única de letramento, tampouco de como pode ser avaliado. Um caminho é lembrar que "não é algo que a pessoa ou tem ou não tem ele é um contínuo, variando do nível mais elementar ao mais complexo 
de habilidade de leitura e escrita e de usos sociais." (SOARES, 2010, p. 89).

Entendemos, de acordo com uma perspectiva fundamentada nos Novos Estudos de Letramento, que a escola precisa ir além do ato de ensinar a ler e a escrever: necessita levar os alunos a usarem a escrita e a leitura de modo que participem das diversas práticas sociais.

Os egressos da Educação de Jovens e Adultos (EJA) entrevistados nesta pesquisa trazem, em suas falas, muitos pontos a serem interligados aos referenciais teóricos utilizados para abordar o tema do letramento e da valorização da escrita, quando descrevem, por exemplo, sua sobrevivência na sociedade contemporânea. Para retratar esses dados, buscamos utilizar das estratégias de retextualização propostas por Marcuschi (2001). Ressaltamos que a passagem da fala para a escrita "não é a passagem do caos para a ordem: é a passagem de uma ordem para outra ordem." (MARCUSCHI, 2001, p. 48); sendo assim, nosso foco não se constitui das marcas linguísticas, mas do conteúdo de fala dos participantes.

Fizemos uso de regras de regulação e idealização do texto falado que se fundam nas estratégias de eliminação e inserção, de modo que a interferência seja focada no código, mantendo o sentido dado: eliminação de marcas interacionais e partes de palavras; introdução da pontuação de acordo com a entoação das falas; retirada de repetições, redundâncias, paráfrases e pronomes egóticos; introdução da paragrafação e pontuação detalhada sem modificação da ordem dos tópicos discursivos (MARCUSCHI, 2001, p. 77- 80).

\section{Análise: concepções de egressos da EJA}

Os corpora que constituem este estudo são resultados de entrevistas com quatro pessoas que retomaram os estudos na fase adulta. A opção por entrevistar esses participantes decorreu do fato de que, apesar de terem frequentado a escola na infância, eles não haviam progredido para além do nível da decodificação. Eles retomaram os estudos na fase adulta motivados pela necessidade de alcançar o domínio da leitura e da escrita, uma vez que não conseguiam compreender o que liam e se viam diante da impossibilidade de ascensão no mercado de trabalho ou, simplesmente, pelo desejo de superar o estigma do 
analfabetismo. Os seus estudos haviam sido interrompidos ainda na etapa inicial do ensino fundamental. Os perfis dos participantes estão expressos abaixo, no Quadro 1.

Quadro 1-Perfil dos participantes

\begin{tabular}{|l|l|l|l|l|}
\hline Nomes fictícios & $\begin{array}{l}\text { Interrupção dos } \\
\text { estudos }\end{array}$ & Sexo & Idade & Profissão \\
\hline Participante 1 - Ico & $2^{\text {a }}$ série & Masculino & 48 anos & Trabalhador rural \\
\hline Participante 2 - Soraia & $3^{\text {a }}$ série & Feminino & 42 anos & Doméstica \\
\hline Participante 3 - Plínio & $4^{\text {a }}$ série & Masculino & 53 anos & Pedreiro \\
\hline Participante 4 - Lígia & $2^{\text {a }}$ série & Feminino & 64 anos & Do lar \\
\hline
\end{tabular}

Fonte: elaboração própria

Cada participante cursou somente certa etapa nessa retomada, de modo que seus estudos foram interrompidos novamente: Lígia fez somente um ano, pois não conseguia enxergar os escritos no quadro; Plínio fez dois anos, porque seus horários de trabalho coincidiam com os das aulas; Soraia até o $9^{\circ}$ ano do ensino fundamental, pois a EJA funcionava como programa provisório e teve fim em sua localidade; o mesmo sucedeu com Ico, que fez até o $2^{\circ}$ ano do ensino médio.

Retratando suas falas, para melhor organização dos dados, decidimos recorrer à análise textual discursiva (MORAES; GALIAZZI, 2011), que possibilita elencar categorias a partir dos dados apresentados.

Na primeira categoria, elencamos a Evasão por motivos sociais. Para tanto, apontamos que os entrevistados são frutos da cultura recente de escolarização no Brasil, já que todos vêm de famílias com baixo ou nenhum grau de escolarização. Todos afirmaram ter abandonado a escola para trabalhar e sobreviver, ou seja, atribuíram à sua condição social da época em que eram crianças os motivos por terem deixado a escola tão cedo.

Percebe-se, assim, que os participantes da pesquisa fizeram parte da realidade excludente da escola, que garantia o acesso, mas não a permanência. Assim, só recentemente foi possível voltarem aos estudos, pois houve uma iniciativa de oferta de EJA, próxima às suas residências, no município de Londrina (PR).

Na segunda categoria, apontamos a Retomada de estudos por questões de trabalho e dificuldades no cotidiano, de modo que voltar a estudar, para esses participantes, foi uma iniciativa motivada pela necessidade de um emprego melhor ou de facilitação de tarefas do 
cotidiano. As falas dos participantes apontam a concepção de escrita como instrumento de ascensão social: afirmam que, quem não tem estudo hoje, passa por maiores dificuldades, devido a restritas oportunidades no mercado de trabalho.

Enquanto Ico e Soraia foram incentivados a retomar os estudos por um parente que é professor, Ligia e Plínio disseram que docentes da escola foram convidá-los em suas casas, o que configura a chamada pública como previsto na LDBEN (BRASIL, 1996), em seu Art. 5º que esclarece sobre o acesso à Educação Básica. No entanto, majoritariamente, a idade se mostrou um obstáculo para os participantes retomarem os estudos, constatação essa possível a partir da análise dos depoimentos, que citam como entraves ao estudo principalmente as questões relacionadas à idade, às limitações físicas e às obrigações junto às famílias.

$\mathrm{Na}$ terceira categoria, podemos elencar a Importância atribuída pela sociedade aos registros escritos e sua certificação, exposta nos depoimentos dos participantes, confirmando uma concepção presente na sociedade contemporânea: a valorização da escrita que se reflete na necessidade de comprovação de seu domínio por meio de registro escrito, quais sejam diplomas e certificados. Esta valorização da escrita e necessidade de comprovação foi incorporada pelos entrevistados e está refletida em suas próprias crenças.

Considerando que os participantes da pesquisa, antes de retornarem à escola, já participavam de práticas de letramento, pautados em saberes não adquiridos por via escolar, saberes marginalizados e associados ao baixo status social, para eles, o término dos estudos significou que seus conhecimentos seriam reconhecidos socialmente, como pudemos observar na fala do participante Ico, transcrita a seguir:

Ico: Então as coisas que eu tinha vontade de fazer, através do certificado, não talvez por você conhecer, [...] só entrava se você tivesse aquele certificado [...]. Então, hoje tem coisas que eu sei do que se trata [...] posso dizer que eu passei olhando [...]. Passei por tudo, ciências, geografia, inglês, matemática, química [...], mas assim, se fosse por conhecimento mesmo, não conseguia passar. 
Ico aponta a importância da certificação, acima do próprio conhecimento adquirido, admitindo que algumas noções ele aprendeu (tem coisas que eu sei do que se trata) e outras não, (se fosse por conhecimento mesmo, não conseguia passar). Mas demonstra ter uma visão crítica ao afirmar que, para ingressar em algum emprego ou cargo, não importava realmente o conhecimento, mas o fato de portar o certificado (não talvez por você conhecer [...], só entrava se você tivesse aquele certificado).

Reiteramos que essa terceira categoria permeia todas as demais, pois a valorização da escrita por parte dos egressos da EJA foi a principal constatação resultante das análises.

Em uma quarta categoria, dos Usos dos conhecimentos escolares nas práticas sociais do cotidiano, apontamos que a partir das declarações sobre a oralidade, os participantes, em sua maioria, demonstraram ter noção de que não utilizam a variante de prestígio, a denominada língua culta, e apesar de perceberem que a fala, assim como a escrita, pode ser mais formal ou mais coloquial e popular, e que a funcionalidade deve pautar os usos linguísticos, sentem-se constrangidos e inferiorizados, com baixa autoestima em relação aos usos que fazem da Língua Portuguesa. Majoritariamente, acreditam que não falam bem o Português, mas que o retorno à escola os ajudou, assim como as práticas sociais de que participam.

Nesse contexto, Soraia relatou que quando está em uma conversa com a sua patroa e suas filhas, tenta, na medida do possível, tomar cuidado com a linguagem que utiliza, já que se trata de pessoas com nível superior de ensino.

Sobre o uso de conhecimentos matemáticos, Soraia relatou que é vendedora, então precisava fazer cálculos para receber corretamente dos seus clientes, porém tinha dificuldades, de modo que para ela o aprendizado da matemática foi muito significativo, já que a utiliza em suas práticas sociais cotidianas. Plínio, que é pedreiro, também relatou que precisa fazer muitas contas, por isso foi a aprendizagem mais significativa. Assim, percebemos o quanto é importante que a escola relacione os conteúdos que ensina com as práticas sociais dos indivíduos que a frequentam, pois são essas que ultrapassam os muros da escola. Não queremos dizer com isso que a escola deva se preocupar somente com o ensino linguístico instrumental, ou utilizar exclusivamente as práticas diretamente relacionadas a atividades laborais. Usufruir da 
literatura e experimentar o fazer poético por meio de trovas, cantorias e outras formas de prazer estético fazem parte de práticas sociais apreciadas na cultura popular.

Quanto ao aumento das práticas de letramento após a retomada dos estudos, a participante Soraia relatou que consegue compreender o que lê, ressaltando que lê o jornal na casa em que trabalha. Além disso, utiliza a escrita em seu trabalho, já que ao receber telefonemas anota os recados, por isso, para ela, dominar a escrita é essencial.

Diante dos dados analisados, constatamos que os participantes utilizam a escrita como apoio à memória, em listas e anotações, para comunicação a distância, em bilhetes ou recados e para obtenção de informação e notícias.

Referente à importância do letramento em suas vidas, todos ressaltam a autonomia que saber ler e escrever proporciona. Ico enfatiza ainda que, após concluir os estudos, às vezes pede ajuda das pessoas para realizar uma leitura, mas somente quando está sem seus óculos. Ele se refere ao período anterior, em que não precisava de óculos, antes de ingressar na EJA, declarando que sempre precisava pedir ajuda, porém hoje não precisa mais de auxílio, uma vez que teve uma melhora significativa na compreensão:

Ico: Eu falava: "Oh moça, lê aqui para mim". Porque eu não conseguia, eu estava vendo, mas não conseguia entender [...]. E hoje de 1 a 10, posso dizer que estou com seis.

A partir desse excerto, é possível deduzir que o participante sabia decodificar, porém não tinha chegado ao nível de compreensão e, após retomar seus estudos, avançou significativamente, como ele próprio defende. Saber ler parece-lhes bastante vantajoso para realização de suas atividades cotidianas, visto que não precisam pedir ajuda de outros:

Ligia: A pessoa quando não sabe ler, ela tem que dar as coisas para os outros lerem. Então, a gente sabendo, pega e lê.

A participante Soraia também atribui relevância às práticas letradas, quando comenta que utiliza a leitura para ver preços, pesquisar, 
compreender o que explicam em bancos, ler papéis entregues em diversos lugares, e que fica triste quando vê alguém pedindo que outra pessoa leia algo, pois considera isso um "sofrimento". Essa concepção relaciona-se ao que Rama (2015) caracteriza como a burocracia da cidade letrada. Essa ideia também é ressaltada na fala de Ico, quando conta sobre como foi tirar sua carteira de habilitação, afirmando que o processo não era tão complexo como é atualmente.

Também em relação às práticas de letramento, podemos elencar depoimentos como o de Soraia, que afirma ler gibis da filha, jornais e revistas sempre que tem tempo livre. Também Ico afirma ter aumentado seu grau de compreensão, mas pondera que o tempo que ficou sem ler atrapalhou de tal forma que hoje ele ainda lê pouco. Essa afirmação nos leva a inferir que ele, apesar de conhecer o código e ter certa compreensão na leitura, não conhece gêneros variados, ficando no nível da leitura informativa.

Outra prática de letramento relatada por esse participante ocorre na esfera religiosa; ao frequentar a igreja, ele acompanha pelo jornal distribuído, dando atenção especial aos cantos e aos refrãos. Os outros participantes também afirmaram que leem pouco. Ligia ressaltou que relê os cadernos da escola, já que não dispõe de material impresso. Ainda afirma que houve certa melhora em sua leitura que, antes desse retorno à escola, era inexistente.

Em relação às práticas de letramento típicas do meio escolar, o participante Ico apresenta uma visão crítica referente aos procedimentos de avaliação:

Ico: Eu passei, fiz tudo aquilo lá, mas você sabe que numa idade dessa, a gente não consegue ter um conhecimento igual essa menina minha (apontando para a filha). Ela sabe o que está fazendo, a gente não. Por exemplo, a gente pegava uma prova de inglês, matemática, como é que uma pessoa que ficou 20 anos fora... né? [...].

Essa afirmação leva à percepção de que as práticas de letramento escolar, associadas ao modelo de letramento autônomo, como provas de inglês e matemática, eram insignificativas, afastadas e deslocadas do mundo cotidiano do participante, pois Ico admite não saber "o que estava fazendo". Por isso, é muito importante que o ensino 
para jovens e adultos seja voltado para o contexto de seu público, a fim de que eles não fiquem deslocados. Neste caso, fica explícito que, na visão do entrevistado, os jovens têm mais facilidade para se adaptar à escola como ela se apresenta hoje; já no caso desse participante, que passou muitos anos sem estudar, não houve vínculo com seus interesses e saberes não escolares.

Nesta perspectiva, a Comparação com outras gerações nos parece uma categoria a ser considerada. Ela se faz presente também nos demais participantes como:

Soraia: A idade atrapalhou bastante, porque teve coisas que a gente estudou na escola e não conseguiu gravar na cabeça, por motivo ... assim de estudar e trabalhar.

Além disso, em outras falas, a participante demonstra sentimento de inferioridade em relação aos jovens, pois declara ter dificuldades para realizar algumas tarefas propostas na escola e também as do cotidiano, apontando que os jovens conseguem realizá-las rapidamente e ainda ajudam os mais velhos.

Nesse sentido, a sexta categoria que elencamos é das Dificuldades que persistem, de modo que os participantes também apontam dificuldades com a escrita, que, em certo modo, não foram todas trabalhadas na escola como comenta Soraia, ao descrever que confunde algumas letras, declarando que seu Português é "fraco na escrita", e que se pudesse voltar a estudar, seria o que ela procuraria aprimorar.

O participante Plínio afirma que aprendeu o básico na escola, mas que não faz grande uso da escrita em seu cotidiano:

Plínio: O básico para fazer anotações [...] porque os serviços que eu faço não necessita muito.

Outra participante, considerando que era praticamente analfabeta até retomar os estudos, afirma que passou a escrever mais e a ler melhor:

Ligia: Antes eu escrevia pouco, agora eu escrevo, leio bem. 
Dominar as convenções da escrita é o desejo mais apontado por todos, em depoimentos que se assemelham ao expresso na fala a seguir:

Ico: Não escrevo bem, porque tem coisa que eu vou escrever é $\mathrm{C}$ eu coloco $\mathrm{S}$. Aquele negócio de plural [...].

Apesar de não ter sido explícita a dificuldade com a leitura, é possível entender que a retomada dos estudos colaborou com um aprimoramento, levando-os a ir além da decodificação, mas não se tornaram leitores de muitos gêneros, pois apontam ler apenas textos curtos, instrucionais ou informativos, presentes no dia a dia.

A sétima e última categoria que elencamos é referente à Ampliação da autoestima, pois os participantes explicitaram que ter acesso à educação formal foi muito significativo, levando à inferência de que se sentiam excluídos socialmente por não terem concluído seus estudos.

Como atesta a participante Soraia, ter interrompido os estudos precocemente trazia certa insegurança, gerando impedimentos de conseguir um emprego, assim como Ico, que relata ter mudado sua autoestima a partir da retomada dos estudos, de modo que hoje ele pode declarar que chegou ao " $2^{\circ}$ grau", que corresponde atualmente à denominação ensino médio. Ele se declarava antes como "um cego no escuro", e afirma que, se tivesse estudado, seria outra pessoa hoje. Discurso que remete a um dos mitos do letramento.

Assim, a partir de excertos como esses, inferimos que os participantes da pesquisa utilizam de discursos midiáticos, já apontados nos estudos de Street (2014), Matencio (2008) e Ratto (2008), para fazerem suas afirmações, como se existisse uma linha entre escolarizados e não-escolarizados que reflete de forma negativa na vida dos que não tiveram acesso à educação formal. Provavelmente, de tanto a sociedade em geral afirmar essa concepção, os participantes se apropriam dela.

Não foi expresso nas falas analisadas nenhum indício de melhoria de emprego, de mudança de classe ou de mobilidade social. No entanto, os participantes afirmam benefícios em relação à continuidade dos estudos, enfatizando o aumento da autoestima e da autonomia diante de algumas práticas do cotidiano. 


\section{Considerações finais}

Diante dos dados, percebemos a existência de sete categorias a serem analisadas e buscamos elencar considerações sobre essas instâncias. A partir da análise, concluímos que os entrevistados apontam a EJA como muito importante, de modo a considerar que é bastante significativo para pessoas que não concluíram a escolarização básica na infância e juventude terem garantido o direito de voltar à escola com possibilidade de conclusão dos estudos.

Enfim, constatamos que o letramento interfere na autoestima dos participantes, pois declararam que ficavam constrangidos ao precisar pedir ajuda para ler e escrever, ou envergonhados ao informar seu nível de instrução. Neste sentido, pode-se dizer que todos os participantes atribuíram aos estudos a possibilidade de melhoria em qualidade de vida.

Percebemos que essas pessoas notam e sentem a violência simbólica ${ }^{3}$ causada pela supervalorização da escrita na sociedade contemporânea, de modo a evidenciarem crenças de que a escolaridade é pressuposto para o sucesso social.

Fazemos, ainda, a ressalva de que a modalidade de ensino EJA deve ir além do ensinar a ler e escrever como mera alfabetização, contextualizando os conteúdos com base nas práticas sociais e culturais de letramento de que os educandos já participam e em outras de que possam vir a participar, para que desenvolvam autonomia em realizar atividades vinculadas aos saberes da cultura letrada e para que consigam aplicar os conhecimentos adquiridos em suas vidas cotidianas.

\footnotetext{
${ }^{3}$ Bourdieu (1992) refere-se como violência simbólica à desigualdade social que não se restringe à falta de bens de consumo material, mas à privação de bens simbólicos, a falta de capital cultural valorizado e prestigiado socialmente, como o conhecimento da cultura letrada, o domínio da variedade de língua culta etc.
} 
Concepções de adultos recém escolarizados...

\section{Referências}

BARTON, David. Literacy practices and literacy events. In: BARTON, David; HAMILTON, Mary et al. Worlds of literacy. Clevedon: Multilingual Matters, 1994.

BARTON, David; HAMILTON, Mary; IVANIC, Roz. Situated Literacies - reading and writing in context. London: Routledge, 2000.

BOURDIEU, Pierre. A economia das trocas simbólicas. São Paulo: Perspectiva, 1992.

BRASIL. Lei 9.394, de 20 de dezembro de 1996. Estabelece as Diretrizes e Bases da Educação Nacional. Brasília: Diário Oficial da República Federativa do Brasil, 1996.

BRASIL. Lei 13.005 de 25 de junho de 2014. Aprova o Plano Nacional de Educação - PNE e dá outras providências. Brasília: Presidência da República. Casa Civil. Subchefia para Assunto Jurídicos, 2014. Disponível em: http://www.planalto.gov.br/ccivil_03/_Ato20112014/2014/Lei/L13005.htm. Acesso em: 18 jul. 2018.

FERREIRA, P. Taxa de analfabetismo tem leve queda, mas país ainda está longe de cumprir meta do PNE. In: O Globo. Rio de Janeiro: Infoglobo Comunicação e Participações S.A., 2017. Disponível em: https://oglobo.globo.com/sociedade/educacao/brasil-ainda-tem-118milhoes-de-analfabetos-segundo-ibge-22211755. Acesso em: 18 jul. 2018.

FREIRE, Paulo. A importância do ato de ler: em três artigos que se completam. São Paulo: Cortez, 2001.

FREIRE, Paulo. Pedagogia da autonomia: saberes necessários à prática educativa. São Paulo: Paz e Terra, 1996.

FREIRE, Paulo. Pedagogia do oprimido. 17. ed. Rio de Janeiro: Paz e Terra, 1987. 
GNERRE, Maurizzio. Linguagem, escrita e poder. Campinas: Martins Fontes, 2001.

KLEIMAN, Angela B. O que é letramento?Modelos de letramento e as práticas de alfabetização na escola. In: KLEIMAN, Angela B. (Org.). Os significados do letramento. Campinas: Mercado de Letras, 2008. p. 15-64.

MARCUSCHI, Luiz. A. Da fala para a escrita: atividades de retextualização. São Paulo, Editora Cortez, 2001.

MATENCIO, Maria L. M. Analfabetismo na mídia: conceitos e imagens sobre o letramento.In: KLEIMAN, Angela B. (Org). Os significados do letramento. Campinas: Mercado de Letras, 2008. p. 239-266.

MORAES, Roque; GALIAZZI, Maria C. Análise textual discursiva. 2. ed. Ijuí: UNIJUÍ, 2011.

OLIVEIRA, Marta. K. Letramento, cultura e modalidades do pensamento. In: KLEIMAN, Angela B. (Org.). Os significados do letramento. Campinas: Mercado de Letras, 2008. p. 147-160.

PARANÁ. Diretrizes curriculares da Educação de Jovens e Adultos. Curitiba: SEED, $2006 . \quad$ Disponível em: http://www.educadores.diaadia.pr.gov.br/arquivos/File/diretrizes/dce_e ja.pdf. Acesso em: 29 ago. 2017.

RAMA, Ángel. A cidade das letras. Tradução de Emir Sader. São Paulo: Boitempo, 2015.

RATTO, Ivani. Ação política: fator de constituição do letramento do analfabeto adulto. In: KLEIMAN, Angela B. (Org.). Os significados do letramento. Campinas: Mercado de Letras, 2008. p. 267-290.

ROJO, Roxane. Letramentos múltiplos, escola e inclusão social. São Paulo: Parábola Editorial, 2009. 
Concepções de adultos recém escolarizados...

SIGNORINI, Inês. Letramento e (in)flexibilidade comunicativa. In: KLEIMAN, Angela B. (Org). Os significados do letramento. Campinas: Mercado de Letras, 2008. p.161-200.

SOARES, Magda. Letramento: um tema em três gêneros. 4. ed. Belo Horizonte: Autêntica Editora, 2010.

SOLÉ, Isabel. Estratégias de leitura. 6. ed. Porto Alegre: Artmed, 1998.

STREET, Brian. V. Letramentos sociais: abordagens críticas do letramento no desenvolvimento, na etnografia e na educação. Tradução de Marcos Bagno. São Paulo: Parábola, 2014.

TFOUNI, Leda.V. Letramento e alfabetização. 3. ed. São Paulo: Cortez, 2000.

\section{Apêndice}

Roteiro para entrevistas semiestruturadas

\begin{tabular}{|c|c|c|}
\hline $\begin{array}{l}\text { 1. Nome: } \\
\text { 2. Idade: } \\
\text { 3. Grau de escolaridade: } \\
\text { 4. Profissão: } \\
\text { 5. No de irmãos: } \\
\text { 6. Profissão e grau de } \\
\text { escolaridade dos pais: } \\
\text { 7. Quantos filhos: } \\
\text { 8. Profissão e grau de } \\
\text { escolaridade dos filhos: } \\
\text { 9. Você usa a internet? } \\
\text { Para quê? } \\
\text { 10. Por que você não } \\
\text { terminou/frequentou a } \\
\text { escola quando criança? } \\
\text { 11. } \\
\text { surgiu/sentiu a vontade } \\
\text { de retomar os estudos? } \\
\text { Por quê? }\end{array}$ & $\begin{array}{l}\text { 12. Alguém te incentivou/ou } \\
\text { desmotivou? Quem? Por } \\
\text { quê? } \\
\text { 13. A escola fica longe da sua } \\
\text { casa? } \\
\text { 14. A idade te atrapalhou? } \\
\text { 15. Você acha que frequentar } \\
\text { a escola, ou não, mudou sua } \\
\text { vida? } \\
\text { 16. Em algum momento ou } \\
\text { situação você sentiu-se } \\
\text { constrangida por não ter } \\
\text { terminado os estudos? } \\
\text { 17. Fecharam-se muitas } \\
\text { portas? Por quê? } \\
\text { 18. O que } \\
\text { pensa/pensava sobre a escola } \\
\text { antes de frequentar? Atendeu } \\
\text { suas expectativas? }\end{array}$ & $\begin{array}{l}\text { 19. É importante saber } \\
\text { ler e escrever? Por quê? } \\
\text { Há alguma vantagem ou } \\
\text { desvantagem? Quais? } \\
20 \text {. Você costuma } \\
\text { escrever? E ler? O quê? } \\
\text { Para quê? } \\
\text { 21. Você tem livros, } \\
\text { revistas, jornais em sua } \\
\text { casa? Quais? } \\
22 \text {. Com qual } \\
\text { frequência? Aumentou } \\
\text { após concluir os } \\
\text { estudos? } \\
\text { 23. Você acha que fala e } \\
\text { escreve bem o } \\
\text { português? Por quê? } \\
24 \text { Você consegue } \\
\text { entender bem os textos } \\
\text { que lê? Por quê? }\end{array}$ \\
\hline
\end{tabular}

Fonte: As autoras. 
Patrícia Batista; Ana Lúcia Almeida; Rosangela Netzel

Recebido em: 05/06/2019

Aceito em: 21/11/2019

Title: Newly-school-enrolled adult's conceptions on writing and literacy 